\title{
Rewritable Polymer Films Based on Topo-Polymerization of Diacetylenes in Poly(propylene carbonate)
}

\author{
Zhenni Zhou, ${ }^{1}$ Wei Wei, ${ }^{1}$ Song Li, ${ }^{2}$ Yue Zhang, ${ }^{1}$ Qingying Yao, ${ }^{1}$ Mingli Ni,,${ }^{* 1}$ \\ Haiyan Peng, ${ }^{, 1}$ Xingping Zhou, ${ }^{1}$ Xiaolin $\mathrm{Xie}^{1}$
}

${ }^{1}$ Key Lab for Material Chemistry of Energy Conversion and Storage, Ministry of Education, School of Chemistry and Chemical Engineering, Huazhong University of Science and Technology, Luoyu Road 1037, Hongshan District, Wuhan 430074, China

${ }^{2}$ State Key Lab of Coal Combustion, School of Energy and Power Engineering, Huazhong University of Science and Technology, Luoyu Road 1037, Hongshan District, Wuhan 430074, China

*Email: mlni@hust.edu.cn (M. L. Ni)

*Email: hypeng@hust.edu.cn (H. Y. Peng)

Supporting Information consists of 13 figures, 1 table and related references 


\section{Contents of Supporting Information}

Figure S1 PCDA/PPC and PCDA/PBS films upon exposure to room light

Figure S2 Polymer solutions before and after $365 \mathrm{~nm}$ light irradiation

Figure S3 Visible light absorption of the PDA/PPC film when irradiated by $365 \mathrm{~nm}$ light

Figure S4 Reversible chromatic switch of polymer films

Figure S5

Table S1 Characteristics of light rewritable materials

Figure S6

Figure S7

Figure S8

Figure S9

Figure S10

Figure S11

Figure S12 DSC curves of the PPC films with varying contents of PDA

Figure S13 TGA curves of PBS films with varying contents of PCDA/PDA.

References
Page S3

Page S3

Page S4

Page S4

Page S5

Page S5

Page S6

Page S6

Page S6

Page S7

Page S7

Page S7

Page S8

Page S8

Page S9 


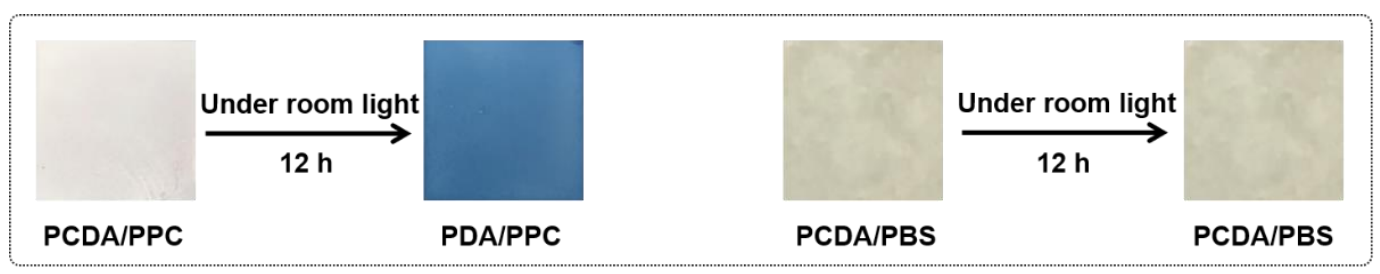

Figure S1. PCDA/PPC and PCDA/PBS films upon exposure to room light for $12 \mathrm{~h}$, respectively. The appearance of blue color indicates the conversion of PCDA to PDA in PPC through polymerization. No polymerization of PCDA occurred in PBS under such a condition. The weight ratio of PCDA/PPC or PCDA/PBS was 1:10.

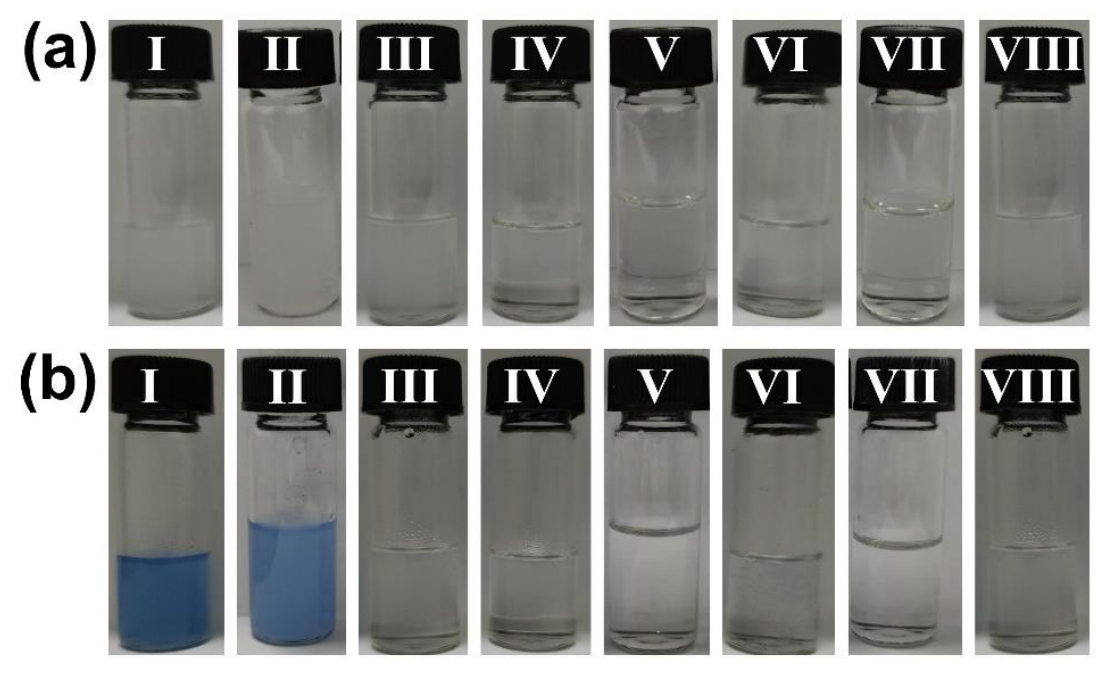

Figure S2. Polymer solutions (a) before and (b) after $365 \mathrm{~nm}$ light irradiation, respectively: (I) PCDA/PPC in $\mathrm{CH}_{2} \mathrm{Cl}_{2}$, (II) PCDA/PPC in acetone, (III) PCDA/PBS in $\mathrm{CH}_{2} \mathrm{Cl}_{2}$, (IV) PCDA/PMMA in $\mathrm{CH}_{2} \mathrm{Cl}_{2}$, (V) PCDA/PMMA in acetone, (VI) PCDA/PVAc in $\mathrm{CH}_{2} \mathrm{Cl}_{2}$, (VII) PCDA/PVAc in acetone, (VIII) PCDA/BAPC in $\mathrm{CH}_{2} \mathrm{Cl}_{2}$. The weight ratio of PCDA to each polymer was 1:10. The irradiation intensity was 60 $\mathrm{mW} / \mathrm{cm}^{2}$ and the irradiation duration was $60 \mathrm{~s}$.

Abbreviations:

PCDA: 10,12-pentacosadiynoic acid

PPC: poly(propylene carbonate), $M_{\mathrm{n}}=1.7 \times 10^{5}, T_{\mathrm{g}} \sim 25^{\circ} \mathrm{C}$

PBS: poly(butylene succinate), $M_{\mathrm{n}}=1.4 \times 10^{5}, T_{\mathrm{g}} \sim-30^{\circ} \mathrm{C}$

PVAc: poly(vinyl acetate), $M_{\mathrm{n}}=5.0 \times 10^{4}, T_{\mathrm{g}} \sim 30^{\circ} \mathrm{C}$

PMMA: poly(methyl methacrylate), $M_{\mathrm{n}}=1.6 \times 10^{5}, T_{\mathrm{g}} \sim 105^{\circ} \mathrm{C}$

BAPC: bisphenol A polycarbonate, $M_{\mathrm{n}}=3.3 \times 10^{4}, T_{\mathrm{g}} \sim 125^{\circ} \mathrm{C}$<smiles>COCCCCOC(=O)CCC(C)=O</smiles>

PBS<smiles>CCC(C)OC(C)=O</smiles>

PVAc<smiles>CCC(C)(C)C(C(=O)OC)(C(C)(C)C)C(C)(C)C</smiles>

PMMA<smiles>CC(C)(C)c1ccc(OC(=O)O[Tl])cc1</smiles>

BAPC 


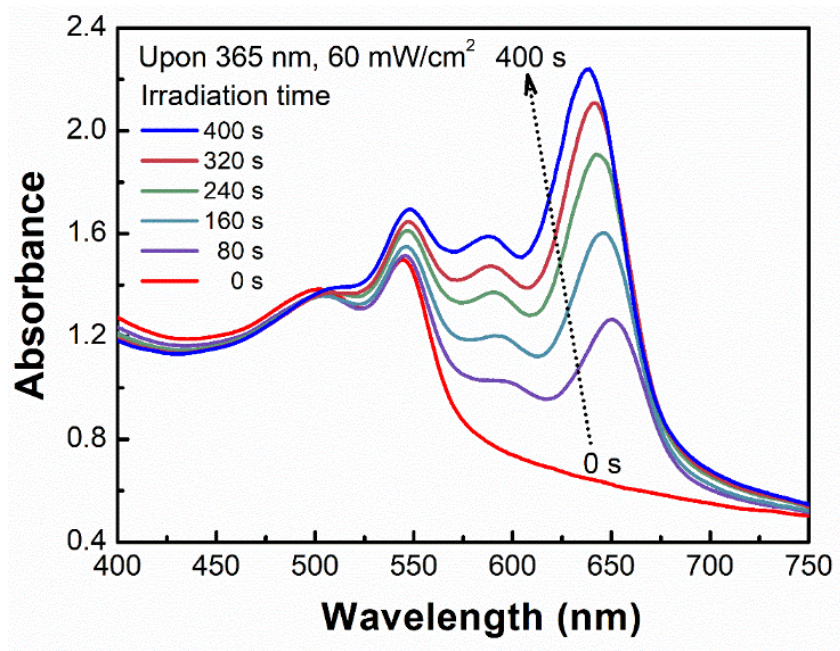

Figure S3. Visible light absorption of the PDA/PPC (1:10 by weight) film when irradiated by $60 \mathrm{~mW} / \mathrm{cm}^{2}$ of $365 \mathrm{~nm}$ light. The red color PDA exhibits peak absorptions at 500 and $550 \mathrm{~nm}$, and the appearance of peak absorptions at 590 and $640 \mathrm{~nm}$ is associated to the color change from bright red to dark blue.

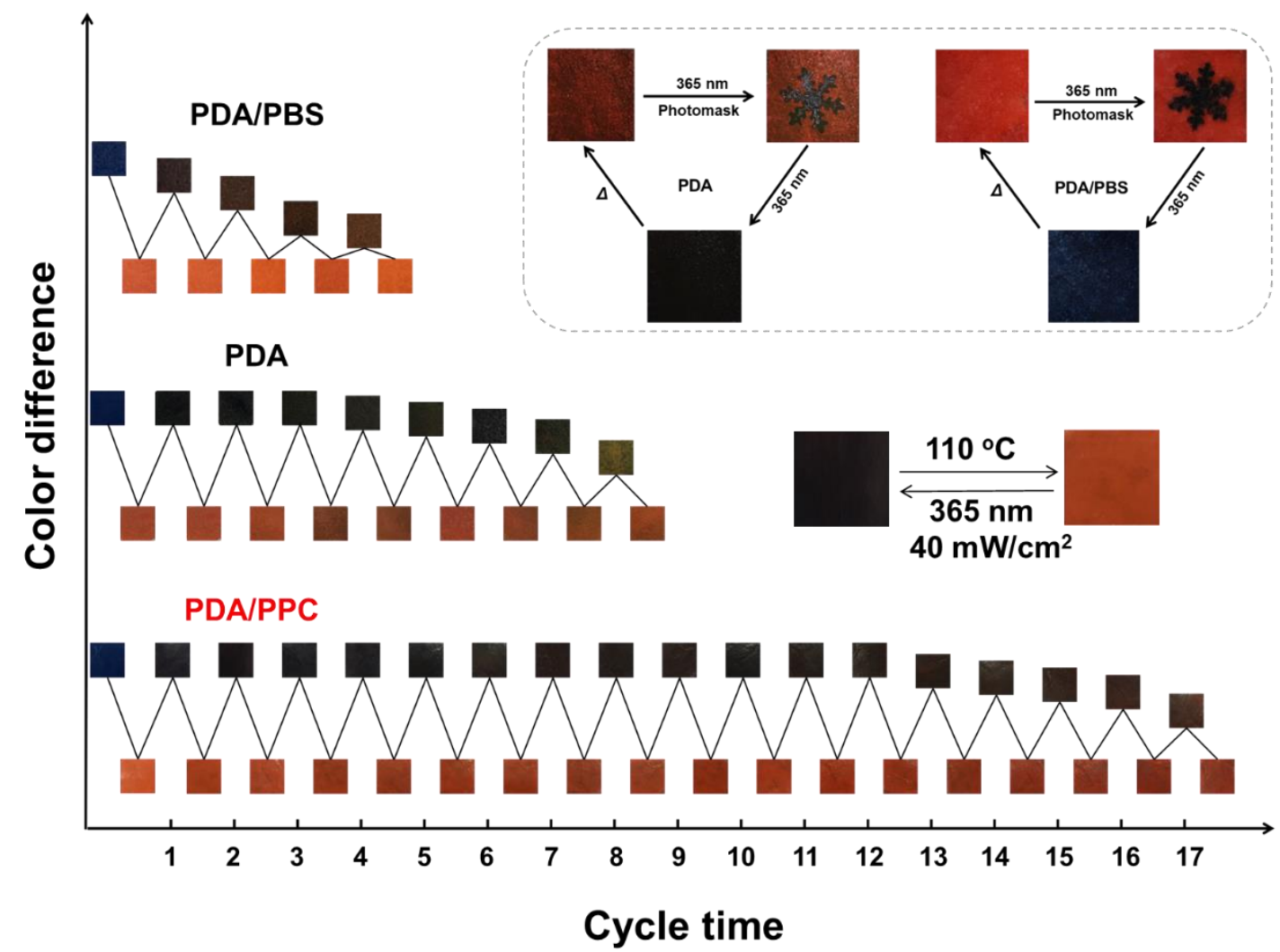

Figure S4. Reversible chromatic switch of polymer films. The insets demonstrate the rewriting capabilities of PDA and PDA/PBS film. 


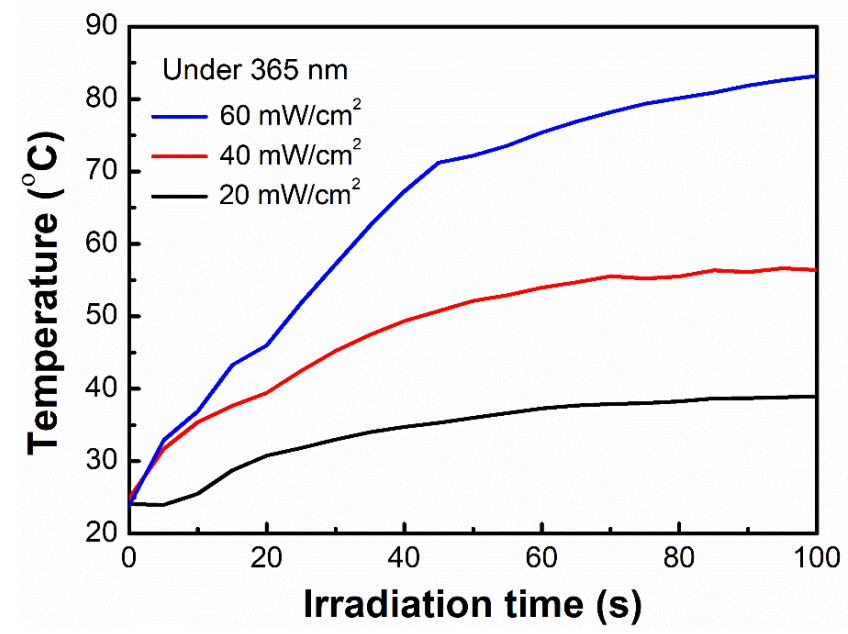

Figure S5. Temperature against irradiation time when irradiated by $365 \mathrm{~nm}$ light with varied intensities.

Table S1. Characteristics of light rewritable materials.

\begin{tabular}{|c|c|c|c|c|}
\hline & $\begin{array}{l}\text { Responsive } \\
\text { time (s) }\end{array}$ & $\begin{array}{l}\text { Rewritable } \\
\text { times }\end{array}$ & $\begin{array}{l}\text { Maintainable } \\
\text { duration (under } \\
\text { room light) }\end{array}$ & Reference \\
\hline diarylethene & 200 & 10 & 3 months & [1] \\
\hline azobenzene/AgNPs & 10 & $\begin{array}{c}\text { Several } \\
\text { hundreds }\end{array}$ & 9 hours & {$[2]$} \\
\hline fulgide & / & 100 & 1 hour & [3] \\
\hline $\mathrm{PVP} / a-\mathrm{WO}_{3}$ & 120 & 40 & 10 days & [4] \\
\hline PS/P2VP & 30 & 50 & / & {$[5]$} \\
\hline$\alpha$-cyanostilbene & 70 & / & 9 hours & [6] \\
\hline polyoxometalate & 180 & 10 & 3 months & [7] \\
\hline prussian blue $/ \mathrm{TiO}_{2}$ & 30 & 80 & $5 \sim 10$ days & [8] \\
\hline redox dyes $/ \mathrm{TiO}_{2}$ & 120 & 20 & several days & [9] \\
\hline $\begin{array}{c}\text { pH-sensitive } \\
\text { dyes/photoacid }\end{array}$ & 2 & 100 & 5 hours & {$[10]$} \\
\hline PDA/PPC & 30 & 17 & $\begin{array}{c}9 \text { months } \\
\text { (under room light) } \\
>12 \text { months } \\
\text { (in dark) }\end{array}$ & this work \\
\hline
\end{tabular}



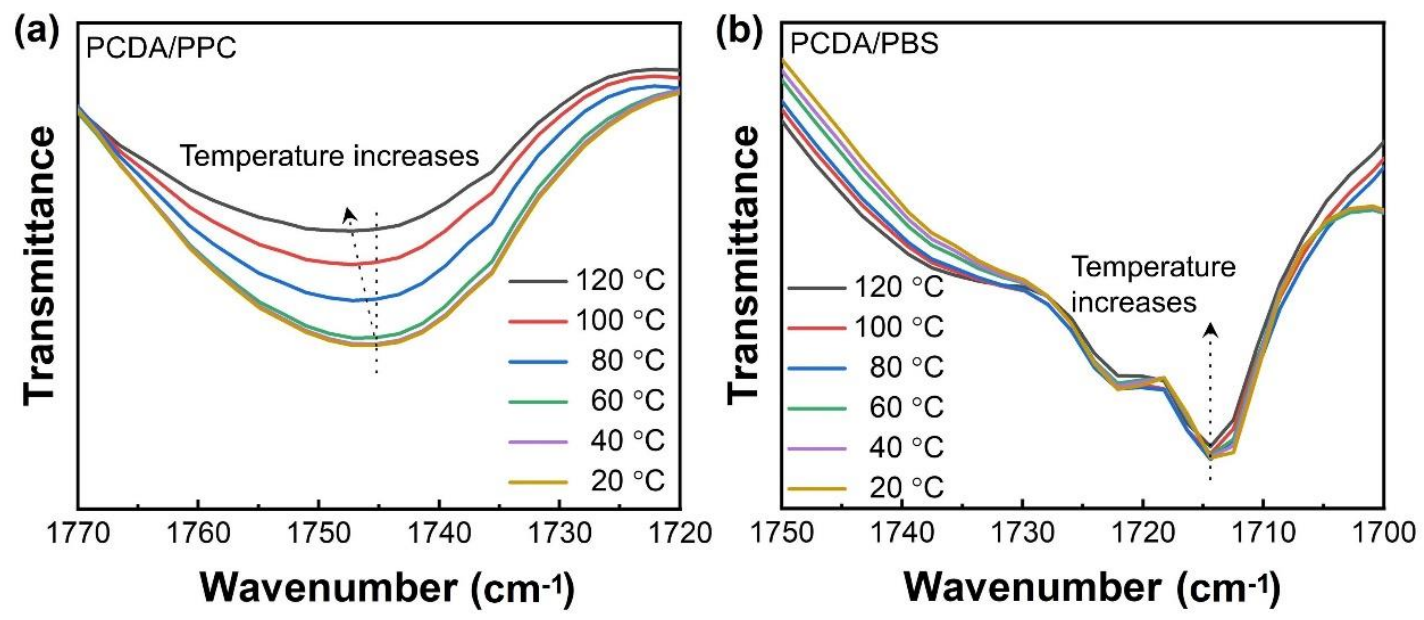

Figure S6. FTIR spectra of (a) PCDA/PPC and (b) PCDA/PBS films under varied temperatures. The weight ratio of PCDA to PPC or PBS is $1: 1$.
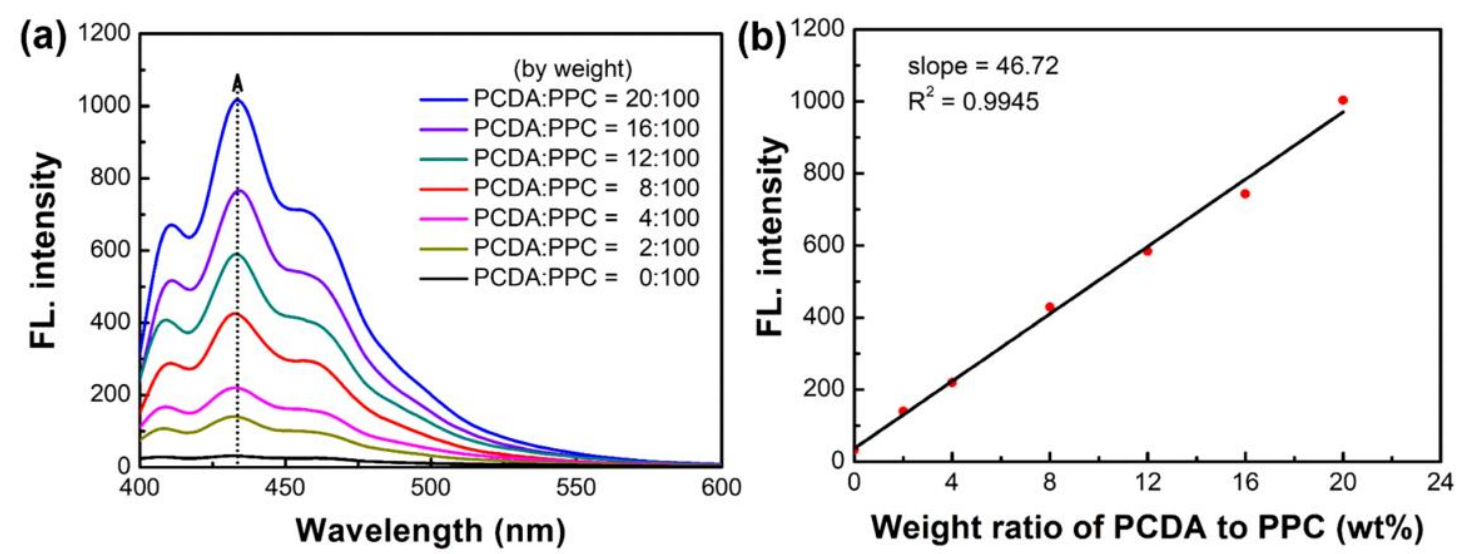

Figure S7. (a) Fluorescence (FL.) spectra of PCDA/PPC films with varying weight ratios. The thickness of each film was fixed at $100 \mu \mathrm{m}$. (b) Linear fitting of the fluorescence intensity against the weight ratio of PCDA to PPC. The fluorescence was excited by $377 \mathrm{~nm}$ light irradiation.

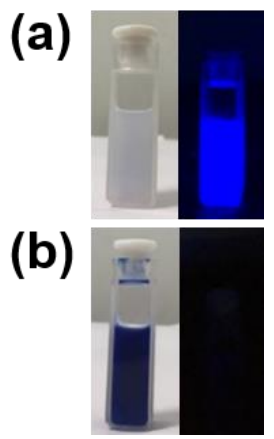

Figure S8. The PCDA/PPC solution in $\mathrm{CH}_{2} \mathrm{Cl}_{2}$ under room light (left) and under UV light (right), respectively, before (a) and after (b) polymerization. The appearance of dark blue color under room light and the disappearance of fluorescence under UV light indicate the polymerization of PCDA. 


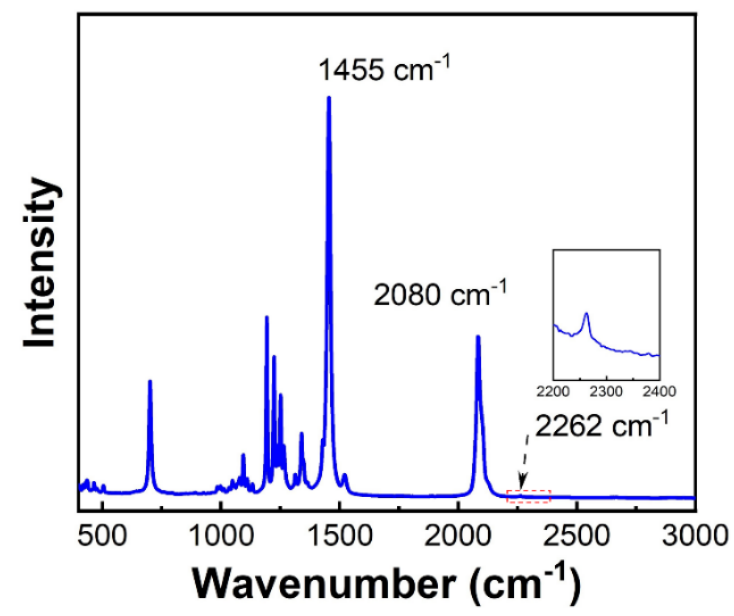

Figure S9. Raman spectrum of the PCDA/PPC (1:10 by weight) film after being exposed to $60 \mathrm{~mW} / \mathrm{cm}^{2}$ of $365 \mathrm{~nm}$ light for $450 \mathrm{~s}$.
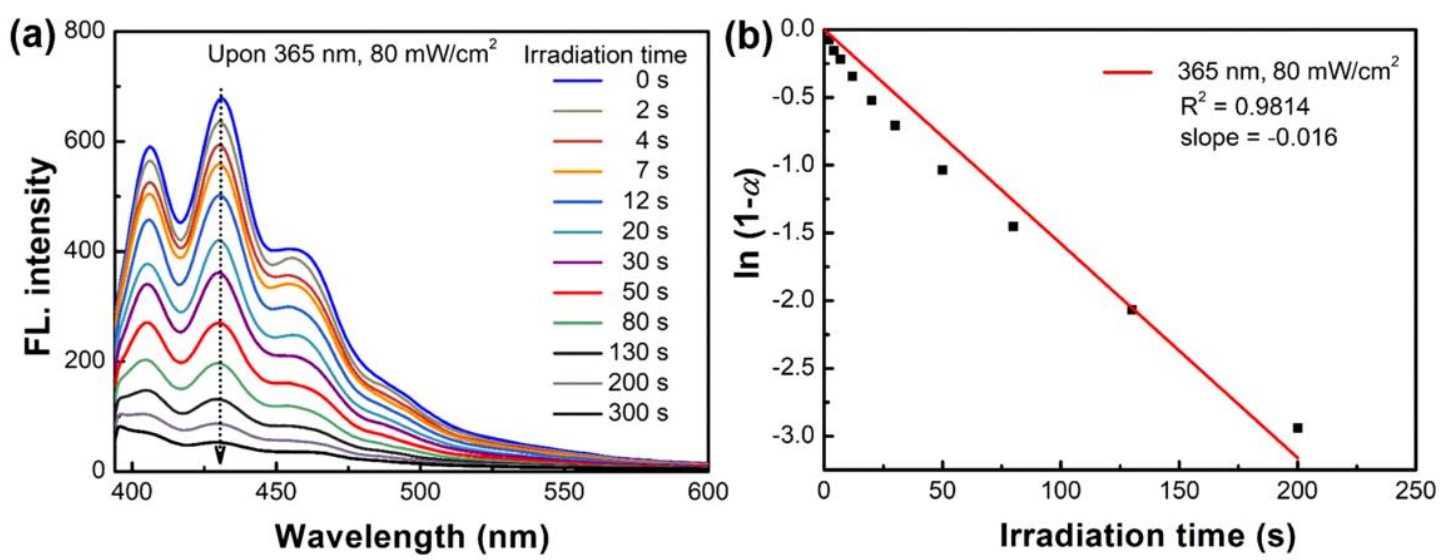

Figure S10. (a) Fluorescence quenching of PCDA/PPC (1:10 by weight) films when exposed to $80 \mathrm{~mW} / \mathrm{cm}^{2}$ of $365 \mathrm{~nm}$ light. (b) Kinetics analysis of the fluorescence quenching. The fluorescence was excited by $377 \mathrm{~nm}$ light irradiation.
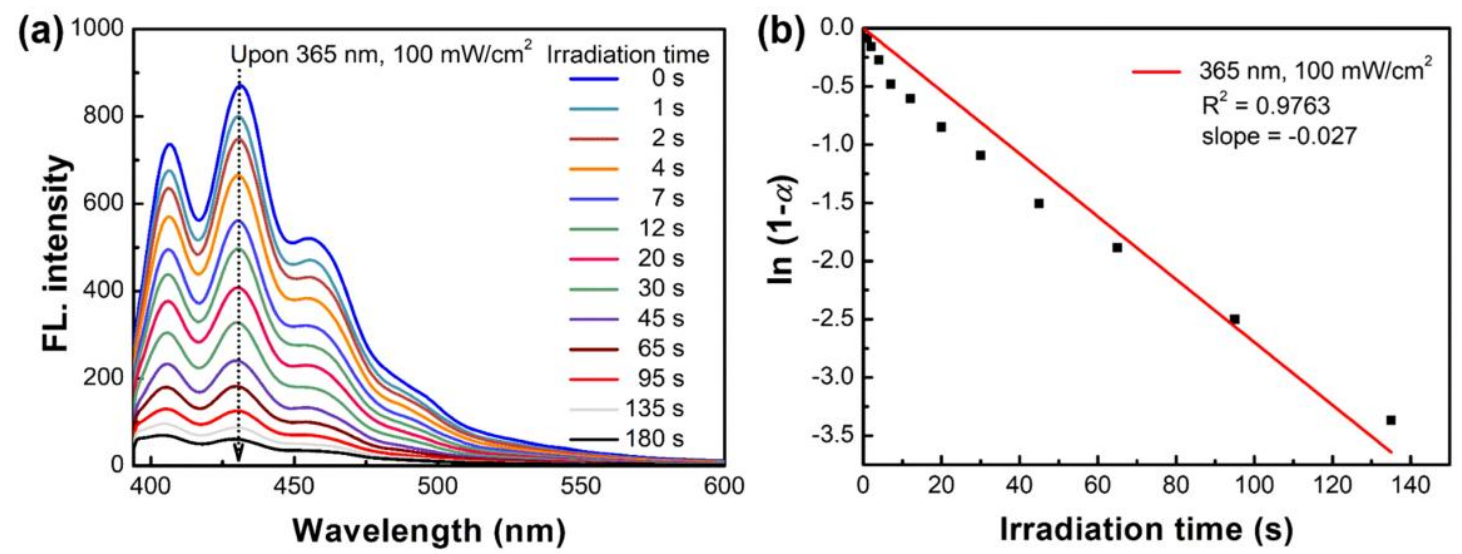

Figure S11. (a) Fluorescence quenching of PCDA/PPC (1:10 by weight) films when exposed to $100 \mathrm{~mW} / \mathrm{cm}^{2}$ of $365 \mathrm{~nm}$ light. (b) Kinetics analysis of the fluorescence quenching. The fluorescence was excited by $377 \mathrm{~nm}$ light irradiation. 


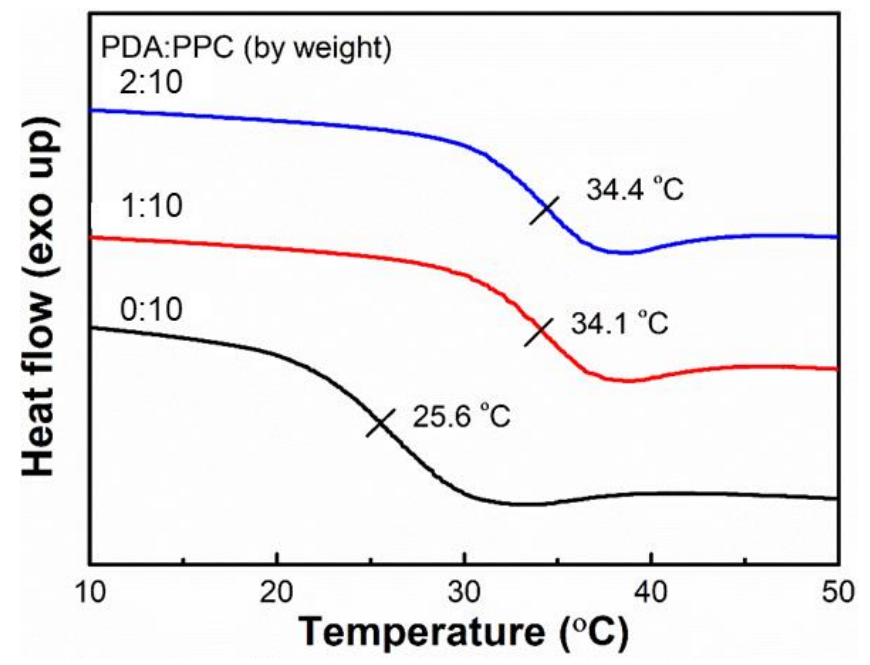

Figure S12. DSC curves of the PPC films with varying contents of PDA.

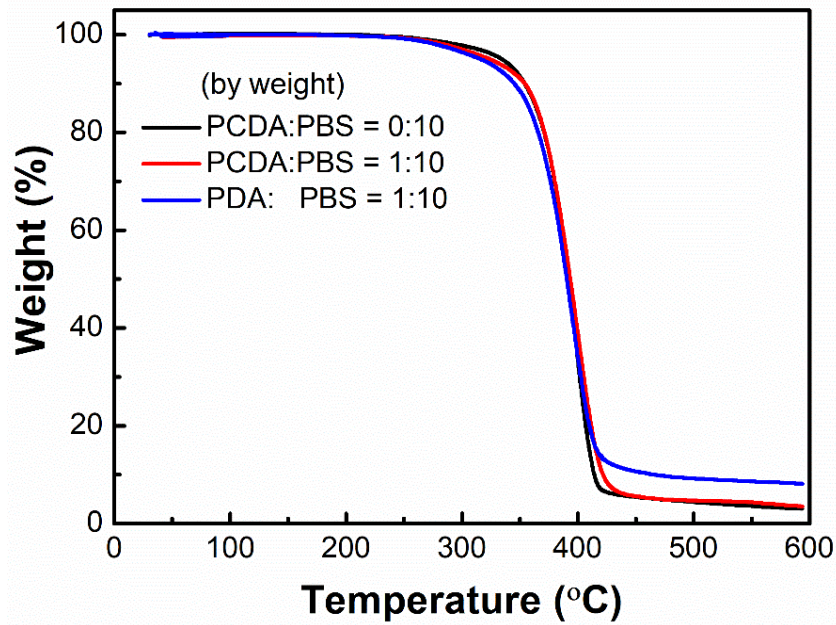

Figure S13. TGA curves of PBS films with varying contents of PCDA or PDA. 


\section{REFERENCES}

[1] Jeong W.; Khazi M. I.; Park D.-H.; Jung Y.-S.; Kim J.-M. Adv. Funct. Mater. 2016, 26, 5230-5238. https://doi.org/10.1002/adfm.201600032

[2] Klajn R.; Wesson P. J.; Bishop K. J.; Grzybowski B. A. Angew. Chem. Int. Ed. 2009, 48, 7035-7039. https://doi.org/10.1002/anie.200901119

[3] Kawashima I.; Takahashi H.; Hirano S.; Matsushima R. J. Soc. Inf. Disp. 2004, 12, 81-85. https://doi.org/10.1889/1.1824243

[4] Wei J.; Jiao X. L.; Wang T.; Chen D. R. ACS Appl. Mater. Interfaces. 2016, 8, 2971329720. https://doi.org/10.1021/acsami.6b10620

[5] Kang H. S.; Lee J.; Cho S. M.; Park T. H.; Kim M. J.; Park C.; Lee S. W.; Kim K. L.; Ryu D. Y.; Huh J.; Thomas E. L.; Park C. Adv. Mater. 2017, 29, 1700084. https://doi.org/10.1002/adma.201700084

[6] Li J. T.; Bisoyi H. K.; Tian J. J.; Guo J. B.; Li Q. Adv. Mater. 2019, 31, 1807751. https://doi.org/10.1002/adma.201807751

[7] Sun H. J.; Gao N.; Ren J. S.; Qu X. G. Chem. Mater. 2015, 27, 7573-7576. https://doi.org/10.1021/acs.chemmater.5b03711

[8] Wang W. S.; Feng J.; Ye Y. F.; Lyu F. L.; Liu Y.-S.; Guo J. H.; Yin Y. D. Nano. Lett. 2017, 17, 755-761. https://doi.org/10.1021/acs.nanolett.6b03909

[9] Wang W. S.; Xie N.; He L.; Yin Y. D. Nat. Commun. 2014, 5, 5459. https://doi.org/10.1038/ncomms6459

[10] Zhang T.; Sheng L.; Liu J. N.; Ju L.; Li J. H.; Du Z.; Zhang W. R.; Li M. J.; Zhang S. X. A. Adv. Funct. Mater. 2018, 28, 1705532. https://doi.org/10.1002/adfm.201705532 